\title{
Effects of Methyl Jasmonate and Caffeic Acid Applications on Secondary Metabolite Production in Madder (Rubia tinctorum) Root Cultures
}

\author{
Pınar Özdamar Biçer', Tunhan Demirci', Özlem Aras AşcI², Nilgün Göktürk Baydar* \\ ${ }^{1}$ Süleyman Demirel University, Agricultural Faculty, Department of Agricultural Biotechnology, 32260 Isparta, TURKEY
}

\begin{abstract}
This study was carried out to determine the effects of methyl jasmonate (MeJA) and caffeic acid (CA) applications on the root growth index and contents of total anthraquinones (AQs), alizarin, purpurin, total phenolic (TP) and individual phenolic compounds in madder (Rubia tinctorum) roots grown in vitro conditions. For this aim, in vitro adventitious roots derived from internode parts were cultured in Murashige and Skoog media containing two different concentrations of MeJA (10 and $100 \mu \mathrm{M})$ and CA (1 and $2 \mathrm{mM})$ for 7 days. Based on the results, MeJA decreased the root growth index compared to control while CA had a positive influence on the root growth of madder. It may be concluded that 2 $\mathrm{mM} C A+100 \mu \mathrm{M}$ MeJA combination was the most suitable application providing the highest $A Q s$ and phenolics.
\end{abstract}

Keywords: Rubia Tinctorum, Root Culture, Caffeic Acid, Methyl Jasmonate, secondary metabolite, madder.

\section{INTRODUCTION}

Madder (Rubia tinctorum L.) is a perennial plant known as the main source of several anthraquinone (AQ) derivatives in its roots and rhizomes. AQs are important compounds not only in textile and food industries regarding dying properties ${ }^{1}$ but also in pharmaceutical industry because of its pharmacological and biological activities. ${ }^{2}$ Because of having antioxidant and biological activities, phenolic compounds are also another unique and valuable metabolite group used in food, cosmetic, perfumery and pharmaceutical industries. So it is important to obtain AQs and phenolics with high quality and quantity in madder. To get economic AQ yield, the most appropriate age is 3 years and collection from nature might result in the danger of extinction of madder in the course of time. Therefore in vitro culture is an important strategy which can be used as an alternative to traditional method in the production of valuable secondary metabolite in plants. Additionally, it is possible to enhance metabolite accumulation by adding several precursors and elicitors to the culture medium. $^{3}$

The aim of this study was to determine the effects of CA and MeJA at different concentrations on root growth and contents of total AQs, alizarin, and purpurin, total phenolic and individual phenolic compounds in adventitious roots of madder under in vitro conditions.

\section{MATERIAL AND METHODS}

\section{Plant Materials}

In this study, adventitious roots derived from internode parts of shoots of three year-old madder were used as plant materials. Adventitious roots from internode parts were obtained by the method of Kubota et al. ${ }^{4}$

\section{Methods}

About $250 \mathrm{mg}$ adventitious roots, were transferred to $30 \mathrm{~mL}$ of $\mathrm{MS}$ liquid medium, containing $30 \mathrm{~g} / \mathrm{L}$ sucrose, in
DOI: 10.5530/ijper.51.3s.76 Correspondence:

Nilgün Göktürk Baydar,

Süleyman Demirel University, Agricultural Faculty, Department of Agricultural Biotechnology, 32260 Isparta, TURKEY

Contact: +902462118560 E-Mail: nilgungbaydar@sdu. edu.tr 
$100 \mathrm{~mL}$ flasks and maintained at $25^{\circ} \mathrm{C}$ on a shaker $(100$ rpm) in a growth chamber under dark conditions. $\mathrm{CA}$ at 1 and $2 \mathrm{mM}$ or MeJA at 10 and $100 \mu \mathrm{M}$ was added separately or together to the root cultures at 7 days after inoculation. Experiments were performed in triplicate and three flasks were used for each replication. After 7 days, roots were harvested, washed with distilled water, weighed, dried and used in the analyses. The growth index of the roots was calculated using the formula "Growth index $=$ (fresh weight of harvested roots -fresh weight of inoculated roots)/ fresh weight of inoculated roots". AQ extractions and spectrophotometric determination of total QA were performed by the method of Shulte et al. ${ }^{5}$ and alizarin and purpurin were determined according to $\mathrm{Shin}^{6}$ and expressed as $\mathrm{mg} / \mathrm{g}$ DW. Phenolics in root samples were extracted twice with $70 \%$ ethanol containing $0.2 \%$ hydrochloride acid in ultrasonic water bath. TP contents were determined spectrophotometrically according to the Folin-Ciocalteu colorimetric method ${ }^{7}$ and expressed as $\mathrm{mg}$ gallic acid equivalents (mg GAE/g DW). Individual phenolics were determined by High Pressure Liquid Chromatography. ${ }^{8}$ Data presented are average of three measurements. Data were performed by using analysis of variance (ANOVA) using SPSS 16.0 for Windows Software Package and the means were separated by Duncan's multiple range tests.

\section{RESULTS AND DISCUSSION}

CA and MeJA applications significantly affected both root growth index as well as secondary metabolite production in root cultures of madder. The highest root growth index (1.37) was found in the cultures treated with $2 \mathrm{mM}$ CA while the lowest growth index was obtained from the roots treated with $100 \mu \mathrm{M}$ MeJA (Fig. 1). Based on these results it can be noticed that root growth of madder was decreased with MeJA and significantly encouraged by CA applications. Similarly, Bulgakov et al. ${ }^{9}$ reported that MeJA inhibited the growth of all Rubia cordifolia callus cultures compared to the control. On the other hand, addition of CA had no influence on cell growth in Cinchona robusta. ${ }^{10}$ This result indicated that, the effects of CA on growth also depend on the culture type and the genotypes.

Secondary metabolites in adventitious roots of madder were affected significantly by the CA and MeJA (Fig. 2) and all applications increased $A Q s$ and phenolics compared to the control. The highest total AQ $(39.45 \mathrm{mg} / \mathrm{g})$, alizarin $(4.44 \mathrm{mg} / \mathrm{g})$, purpurin $(0.80 \mathrm{mg} / \mathrm{g})$ and TP $(40.30 \mathrm{mg} / \mathrm{g})$ were found in roots treated with $2 \mathrm{mM} \mathrm{CA}+100 \mu \mathrm{M}$ MeJA combination. Upon analysing the results, high concentrations of MeJA $(100 \mu \mathrm{M})$ and CA $(2 \mathrm{mM})$ had

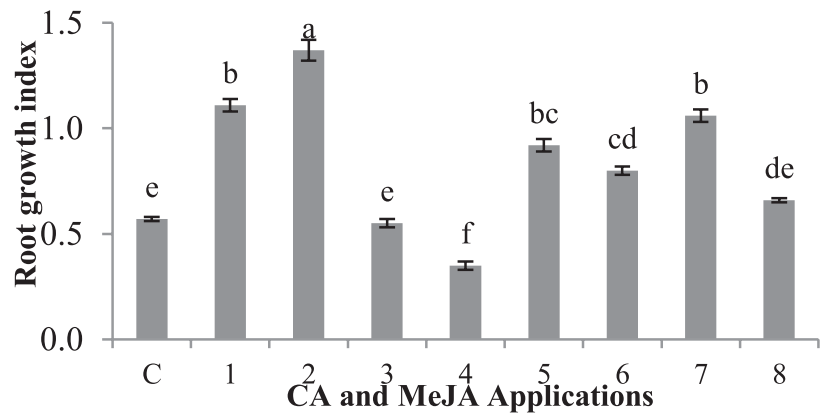

Figure 1: Effects of MeJA and CA applications on the growth index of roots (C: control, 1: $1 \mathrm{mM} \mathrm{CA}, 2: 2 \mathrm{mM} \mathrm{CA}, 3: 10 \mu \mathrm{M}$ MeJA, 4: $100 \mu \mathrm{M}$ MeJA, 5: $1 \mathrm{mM}$ CA+10 $\mu \mathrm{M}$ MeJA, 6: $1 \mathrm{mM}$ CA+100 $\mu \mathrm{M}$ MeJA, 7: 2 mM CA+10 $\mu$ M MeJA, 8: 2 mM CA+100 $\mu \mathrm{M}$ MeJA).

a greater potential on metabolite production than low concentrations of them. But the stimulating effect of MeJA on the accumulations of AQs and phenolics was higher than CA. Individual phenolic compound concentrations also varied depending on the applications (Table 1). All MeJA and CA applications increased the phenolic compounds compared to control. The highest contents of gallic acid, o-coumaric acid, $p$-coumaric acid, chlorogenic acid and caffeic acid were obtained from the $2 \mathrm{mM}$ $\mathrm{CA}+100 \mu \mathrm{M}$ MeJA application. On the other hand the maximum catechin, rutin, ferulic acid, cinnamic acid and quercetin amounts were obtained from the $100 \mu \mathrm{M}$ MeJA applications without regard to CA.

MeJA was used in this study to enhance the accumulation of AQ and phenolics in root cultures of madder. It is well known that MeJA plays a key role in co-ordination of plant defence gene expression. ${ }^{9}$ It is a signalling and regulatory molecule influencing enzymes of the biosynthetic pathway responsible for secondary metabolite accumulation. ${ }^{11}$ The induction effect of MeJA on AQ production in root cultures of madder was in agreement with reported data which revealed that MeJA strongly increased AQ accumulation in genius Rubia.9-12,13 According to Mantrove et al. ${ }^{13}$ MeJA stimulates the biosynthesis of a key enzyme involved in the AQ biosynthesis in madder roots. According to Schripsema et al., ${ }^{14}$ AQs are derived from CA or another phenylpropanoid. But Han et al. ${ }^{15}$ showed that CA is unlikely intermediate in $\mathrm{AQ}$ biosynthesis in their feeding experiments with $[1-13 C]$ glucose. Even if CA is not an intermediate in AQ synthesis, in another study, feeding of CA resulted in a $48 \%$ increase in AQ accumulation compared to the control in cell cultures of Cinchona 'Robusta' by activation of other pathways. ${ }^{10}$ Besides, MeJA had positive effects on the production of phenolics in vitro cultures of different plants. ${ }^{16,17}$ These results suggest that the effects 

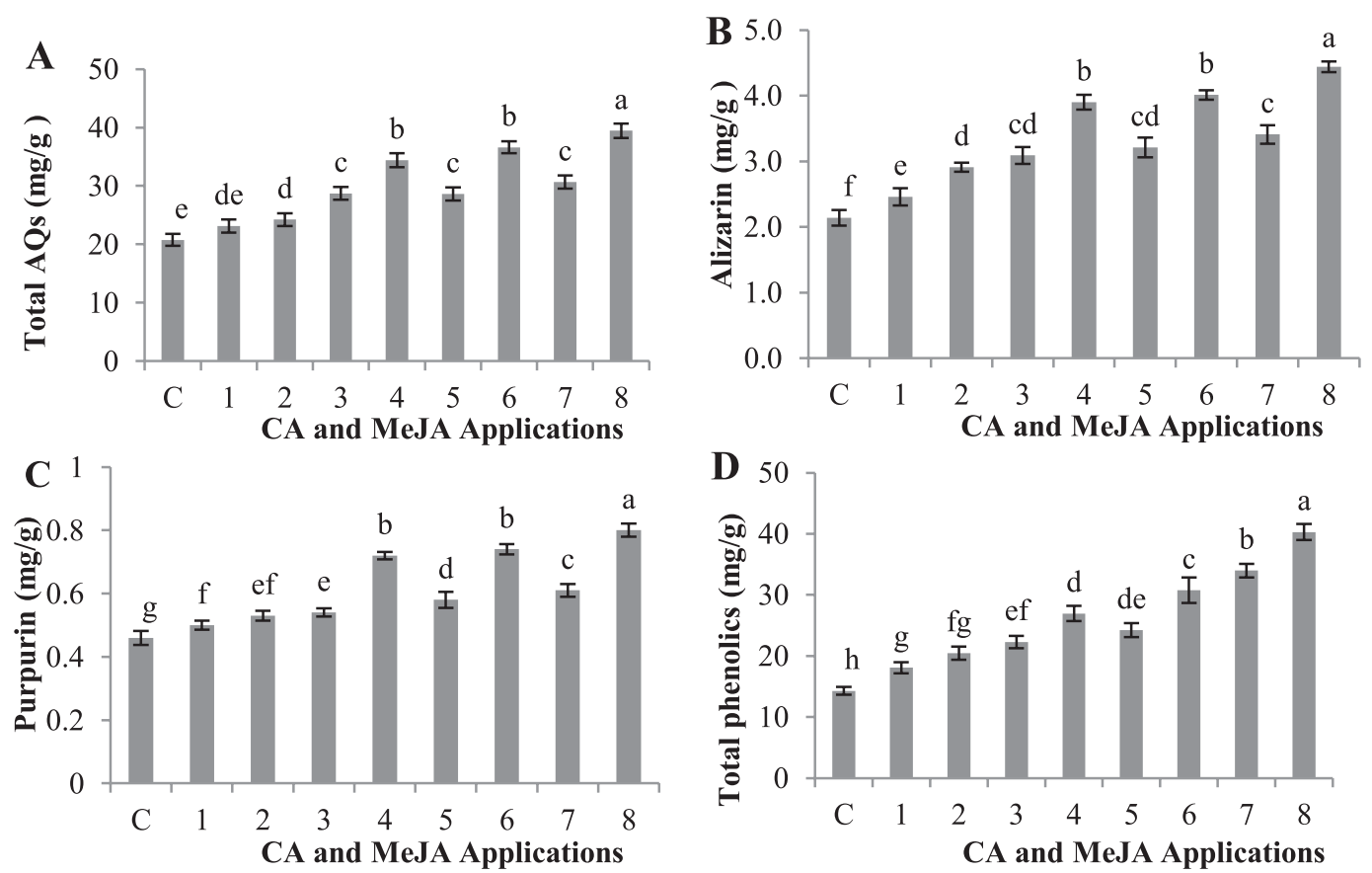

Figure 2. Effects of MeJA and CA applications on total $A Q(A)$, alizarin (B), purpurin (C) and total phenolic (D) contents of roots (C: control, 1:1 mM CA, 2: 2 mM CA, 3: $10 \mu \mathrm{M}$ MeJA, 4: $100 \mu \mathrm{M}$ MeJA, 5: 1 mM CA+10 $\mu$ M MeJA, 6: 1 mM CA+100 $\mu$ M MeJA, 7: 2 $\mathrm{mM} \mathrm{CA+10} \mu \mathrm{M}$ MeJA, 8: 2 mM CA+100 $\mu \mathrm{M}$ MeJA).

\begin{tabular}{|c|c|c|c|c|c|c|c|c|c|c|}
\hline & $\begin{array}{c}\text { Gallic } \\
\text { acid }\end{array}$ & Catechin & $\begin{array}{c}o- \\
\text { coumaric } \\
\text { acid }\end{array}$ & $\begin{array}{l}\text { Cinnamic } \\
\text { acid }\end{array}$ & $\begin{array}{c}p \text {-coumaric } \\
\text { acid }\end{array}$ & $\begin{array}{c}\text { Chlorogenic } \\
\text { acid }\end{array}$ & $\begin{array}{c}\text { Caffeic } \\
\text { acid }\end{array}$ & $\begin{array}{c}\text { Ferulic } \\
\text { acid }\end{array}$ & Rutin & Quercetin \\
\hline $\mathrm{C}^{*}$ & $0.27 \mathrm{f}$ & $0.26 \mathrm{f}$ & $0.96 \mathrm{f}$ & $2.36 \mathrm{e}$ & $0.48 \mathrm{~g}$ & $0.08 \mathrm{c}$ & $0.08 \mathrm{f}$ & $0.18 \mathrm{c}$ & $0.26 \mathrm{~d}$ & $0.19 \mathrm{e}$ \\
\hline 1 & $0.36 \mathrm{e}$ & $0.32 \mathrm{de}$ & $1.26 \mathrm{e}$ & $3.49 \mathrm{~d}$ & $0.57 \mathrm{f}$ & $0.16 \mathrm{~b}$ & $0.11 \mathrm{e}$ & $0.28 b$ & $0.32 \mathrm{c}$ & $0.28 d$ \\
\hline 2 & $0.40 \mathrm{e}$ & $0.37 \mathrm{~cd}$ & $1.31 \mathrm{e}$ & $3.52 \mathrm{~d}$ & 0.62 ef & $0.16 \mathrm{~b}$ & $0.12 \mathrm{e}$ & $0.29 \mathrm{~b}$ & $0.37 \mathrm{bc}$ & $0.27 \mathrm{~d}$ \\
\hline 3 & $0.49 \mathrm{~d}$ & $0.38 \mathrm{~cd}$ & $1.59 \mathrm{~d}$ & $4.18 \mathrm{c}$ & $0.68 \mathrm{e}$ & $0.17 \mathrm{~b}$ & $0.12 \mathrm{e}$ & $0.28 b$ & $0.39 \mathrm{~b}$ & $0.28 d$ \\
\hline 4 & $0.51 \mathrm{~d}$ & $0.50 a$ & $1.65 \mathrm{~cd}$ & $5.87 \mathrm{a}$ & $0.86 \mathrm{~d}$ & $0.18 b$ & $0.14 \mathrm{~d}$ & $0.34 \mathrm{a}$ & $0.53 a$ & $0.63 a$ \\
\hline 5 & $0.53 \mathrm{~cd}$ & $0.40 \mathrm{bc}$ & $1.71 \mathrm{bcd}$ & $4.85 b$ & $0.88 d$ & $0.18 \mathrm{~b}$ & $0.16 \mathrm{c}$ & $0.27 \mathrm{~b}$ & $0.36 \mathrm{bc}$ & $0.45 \mathrm{c}$ \\
\hline 6 & $0.68 \mathrm{~b}$ & $0.51 \mathrm{a}$ & $1.83 b c$ & $5.88 \mathrm{a}$ & $1.07 \mathrm{~b}$ & $0.19 b$ & $0.18 b$ & $0.38 a$ & $0.51 \mathrm{a}$ & 0.67 a \\
\hline 7 & $0.61 \mathrm{bc}$ & $0.44 \mathrm{~b}$ & $1.88 \mathrm{~b}$ & $4.87 \mathrm{~b}$ & $0.98 \mathrm{bc}$ & $0.19 b$ & $0.17 \mathrm{bc}$ & $0.27 b$ & $0.36 \mathrm{bc}$ & $0.54 \mathrm{~b}$ \\
\hline 8 & $0.77 \mathrm{a}$ & $0.49 a$ & $3.08 \mathrm{a}$ & $5.97 \mathrm{a}$ & $1.18 \mathrm{a}$ & $0.22 \mathrm{a}$ & $0.23 a$ & $0.36 \mathrm{a}$ & $0.52 \mathrm{a}$ & $0.69 a$ \\
\hline
\end{tabular}

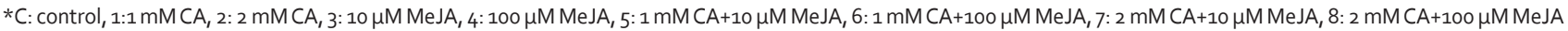

of MeJA and CA on secondary metabolite production seem to be due to the activation of related metabolism.

\section{CONCLUSION}

Based on the results, it may be concluded that MeJA treatments decreased growth index but induced secondary metabolite accumulation. CA increased both growth index as well as AQ and phenolics. Another interesting result is that the highest $\mathrm{AQ}$ and phenolic accumulations were obtained when MeJA and CA were used together at high concentrations in comparison with the other applications. For this reason combination of $2 \mathrm{mM}$ CA and $100 \mu \mathrm{M}$ MeJA was found as an optimum application for secondary metabolites accumulation because of giving the maximum AQs and phenolics in root cultures of madder.

\section{ACKNOWLEDGMENTS}

The authors are thankful to Süleyman Demirel University Scientific Research Projects Coordination Unit for the financial support for this research Project. 


\section{CONFLICT OF INTEREST}

The authors declare No conflict of Interest

\section{ABBREVIATION USED}

AQ: Anthraquinone; AQs: Antraquinones; CA: Caffeic acid; DW: Dry Weight; GAE: Gallic Acid Equivalent; MeJA: Methyl Jasmonate; MS: Murashige and Skoog; TP: Total Phenolic.

\section{REFERENCES}

1. Baydar $\mathrm{H}$, Karadogan T. Agronomic potential and industrial value of madder (Rubia tinctorum L.) as a dye crop. Turkish Journal of Agriculture and Forestry 2006;30:287-93.

2. Siva R, Palackan MG, Maimoon L, Geetha T, Bhakta D, Balamurugan P, Rajanarayanan S. Evaluation of antibacterial, antifungal, and antioxidant properties of some food dyes. Food Science and Biotechnology. 2011;20(1):7-13.

3. Karuppusamy S. A review on trends in production of secondary metabolites from higher plants by in vitro tissue, organ and cell cultures. Journal of Medicinal Plants Research. 2009;3(13):1222-39.

4. Kubota H, Sato K, Yamada T, Maitani T. Phytochelatins (class III metallothioneins) and their desglycyl peptides induced cadmium in normal root cultures of Rubia tinctorum. Plant Science. 1995;110:157-66.

5. Schulte U, El-Shagi H, Zenk MN. Optimization of Rubiaceae species in cell culture for the production of anthraquinones. Plant Cell Reports. 1984;3:51-4.

6. Shin $\mathrm{SH}$. Studies on the production of anthraquinone derivatives by tissue culture of Rubia species. Archives of Pharmacal Research. 1989;12:99-102.

7. Singleton VL, Rossi JR. Colorimetry of total phenolics with phosphomolybdicphosphotungstic acid. American Journal of Enology and Viticulture 1965; 16:144-158

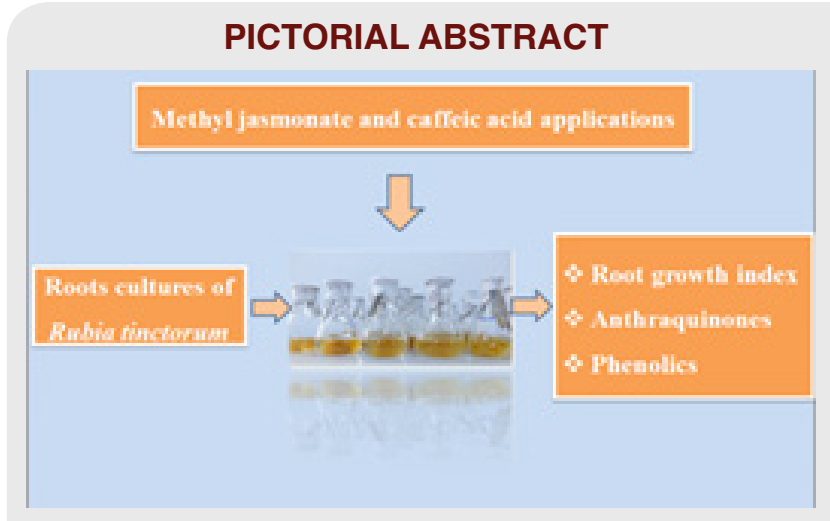

\section{ABOUT AUTHORS}

MSc. Pinar Özdamar Biçer: She completed her Master of Science Degree in Agricultural Biotechnology

Department of Süleyman Demirel University.
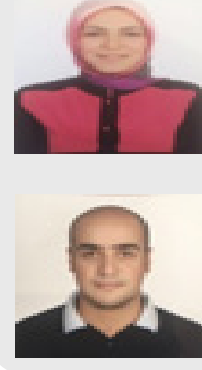

Dr. Tunhan Demirci: He has experience in the area of aromatic and medicinal plants, gene transfer techniques and secondary metabolites. He has published a number of papers in various journals. 


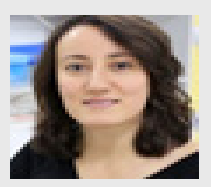

Dr. Özlem Aras Aşci: She is presently working as Dr. in Agricultural Biotechnology Deparment in Süleyman Demirel University. She has experience in tissue culture and secondary metabolites. She has published a number of papers in different journals.

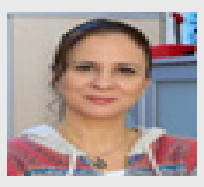

Dr. Nilgün Göktürk Baydar: She is presently working as Professor in Deparment of Agricultural Biotechnology in Süleyman Demirel University. She has experience in stress physiology, plant biotechnology and secondary metabolites. She has got a lot of papers in her expertise area in various journals.

Cite this article: Biçer PÖ, Demirci T, Asci ÖA, Baydar NG. Effect of Methyl Jasmonate and Caffeic Acid Applications on Secondary Metabolite Production in Madder (Rubia Tinctorum) Root Cultures. Indian J of Pharmaceutical Education and Research. 2017;51(3)Suppl:S508-12. 